\title{
Selectively increasing of polyunsaturated (18:2) and monounsaturated (18:1) fatty acids in Jatropha curcas seed oil by crystallization using D-optimal design
}

\author{
Jumat Salimon*, Bashar Mudhaffar Abdullah and Nadia Salih
}

\begin{abstract}
Background: This study was done to obtain concentrated polyunsaturated fatty acid (PUFA) linoleic acid (LA; 18:2) and monounsaturated fatty acid (MUFA) oleic acid (OA; 18:1) from Jatropha curcas seed oil by urea complexation. Urea complexation is a method used by researchers to separate fatty acids (FAs) based on their molecular structure. Effects the ratio of urea-to-FAs, crystallization temperature and crystallization time on the final products of urea complexation were examined. D-optimal Design was employed to study the significance of these factors and the optimum conditions for the technique were predicted and verified.

Results: Optimum conditions of the experiment to obtain maximum concentration of LA were predicted at urea-to-FAs ratio ( $\mathrm{W} / \mathrm{W}$ ) of $5: 1$, crystallization temperature of $-10^{\circ} \mathrm{C}$ and $24 \mathrm{~h}$ of crystallization time. Under these conditions, the final non-urea complex fraction (NUCF) was predicted to contain $92.81 \%$ of LA with the NUCF yield of $7.8 \%$. The highest percentage of OA (56.01\%) was observed for samples treated with 3:1 urea-to-FAs ratio (w/W) at $10^{\circ} \mathrm{C}$ for $16 \mathrm{~h}$. The lowest percentage of LA (8.13\%) was incorporated into urea complex fraction (UCF) with 1:1 urea-to-FAs ratio $(\mathrm{W} / \mathrm{W})$ at $10^{\circ} \mathrm{C}$ for $8 \mathrm{~h}$.

Conclusions: The separation of PUFA (LA) and MUFA (OA) described here. Experimental variables should be carefully controlled in order to recover a maximum content of PUFA and MUFA of interest with reasonable yield\% with a desirable purity of fatty acid of interest.
\end{abstract}

Keywords: D-optimal design, Optimization, Polyunsaturated, Monounsaturated, Linoleic acid, Oleic Acid

\section{Background}

Linoleic acid (LA) [also called cis,cis,-9,12-octadecadienoic acid] is an example of a polyunsaturated fatty acid (PUFA), due to the presence of two carbon double bonds. The high content of LA makes Jatropha curcas seed oil very important for industry use. LA can be used in protective coatings, plastics, surfactant, dispersants, biolubricant, and a variety of synthetic and in the preparations of other long chain compounds. The high content of LA in seed oil of $J$. curcas is very important to the production of oleo-chemicals [1]. Oleic acid (OA) [also called $(9 \mathrm{z})$ - octadec-9-enoic acid] is an example of

\footnotetext{
* Correspondence: jumat@ukm.my

School of Chemical Sciences and Food Technology, Faculty of Science and Technology, Universiti Kebangsaan Malaysia, 43600, Bangi, Selangor, Malaysia
}

a monounsaturated fatty acid (MUFA). A small amount of $\mathrm{OA}$ is used in the pharmaceutical industry, as an emulsifying agent in aerosol products [2].

There are several methods which can be used to obtain polyunsaturated fatty acids (PUFA) including freezing crystallization, urea complexation, molecular distillation, supercritical fluid extraction, silver ion complexation and lipase concentration [3] as well as high-performance liquid chromatography [4]. The most economic and most efficient technique to obtain LA in the form of fatty acids (FAs) is urea complex fractionation. This is a well-established technique for the elimination of saturated fatty acids (SFAs) and MUFA [5].

Urea complexation has the advantage that the complex crystals are extremely stable, and filtration is not carried 
out at low temperatures which is required for solvent crystallization of FAs. This method is preferred by many researchers because complexation depends upon configuration of the FAs moieties due to the presence of multiple double bonds, rather than pure physical properties such as melting point or solubility [5,6]. The SFAs and MUFA easily form complexes with urea and crystallize out at cooling during urea complex fraction (UCF). These complexes can subsequently be removed by filtration. The liquid or non-urea complex fraction (NUCF) is enriched with PUFA and the crystals formed or UCF consists of SFAs and MUFA.

In this study, urea complex fractionation of a mixture of FAs of Malaysian J. curcas seed oil was carried out to obtain concentrated PUFA. The effects of urea-to-FAs ratio, crystallization temperature and crystallization time to the yield\% of NUCF $\left(Y_{1}\right)$, yield\% of UCF $\left(Y_{5}\right)$, percentage MUFA (OA) $\left(Y_{3}\right.$ and $\left.Y_{7}\right)$ and percentage PUFA (LA) $\left(Y_{4}\right.$ and $\left.Y_{5}\right)$ in NUCF and UCF were systematically studied.

\section{Results and discussion}

Non-urea complex fraction (NUCF)

The original fatty acids (FAs) mixture was composed of $13.19 \%$ palmitic (16:0), $6.37 \%$ stearic (18:0), $43.33 \%$ oleic (18:1) and 36.71\% linoleic (18:2) acid. Average molecular weight of the FAs was 203.36 as obtained from saponification test of the original oil. The results compared well with those of [7]. The PUFA (LA) concentrate was prepared by urea complex fractionation following the technique of [8], using the FAs that was previously obtained. The purpose of this procedure was to obtain a PUFA concentrate enriched in LA and simultaneously, maintain the highest yield\% of LA. The crystallization process with urea preferentially selects SFAs and MUFA, and the tendency of FAs to combine with urea decreases with increasing chain lengths [9].

In this study, variations of factors that affect the urea complex fractionation such as the ratio of urea-to-FAs $(\mathrm{w} / \mathrm{w})$, crystallization temperature $\left({ }^{\circ} \mathrm{C}\right)$ and crystallization time (h) were examined to obtain optimum conditions using the response surface method D-optimal design. Table 1 shows data obtained from the experiment on FAs composition in the NUCF of all the samples. Results showed that the percentage of LA has increased from $36.71 \%$ to as much as $92.81 \%$ while SFAs $(0.33 \%)$ has been reduced considerably compared to the initial FAs mixture. In samples with high ratio of urea-to-FAs, the elimination of SFAs was near completion in NUCF. However, total removal of oleic, palmitic and stearic acids by urea complexation may be impossible because some of the SFAs do not form complexes with urea during crystallization [10]. These results demonstrate that oleic, palmitic and stearic acids have more tendencies to form urea adducts than LA.

The LA\% derived from the NUCF phase was relatively high, and some even greater than $90 \%$ under certain experimental conditions (Table 1). This showed that the experimental conditions were suitable for the preparation of high purity LA. However, it is difficult to completely remove all the SFAs and MUFA to obtain 100\% purity of PUFA in the concentrate. [11] reported that complete removal of SFAs and MUFA by urea complexation may be impossible since some of the SFAs do not bind with urea during crystallization.

The quadratic regression coefficient obtained by employing a least squares method to predict quadratic polynomial models for the yield\% of NUCF $\left(Y_{1}\right)$, percentage of SFAs (palmitic and stearic acids) $\left(Y_{2}\right)$, percentage of MUFA (OA) $\left(Y_{3}\right)$ and percentage of PUFA (LA) $\left(Y_{4}\right)$ in NUCF are given in Tables 2, 3, 4 and 5 respectively.

Examination of these coefficients with a $T$-test shows that the percentage yield of NUCF $\left(Y_{1}\right)$, percentage of MUFA (OA) $\left(Y_{3}\right)$, percentage of PUFA (LA) $\left(Y_{4}\right)$, the linear term of urea-to-FAs ratio $\left(X_{1}\right)$ and quadratic term of urea-to-FAs were highly significant $(p<0.01)$, while the percentage of SFAs $\left(Y_{2}\right)$, the linear term was significant at $p<0.05$. Lastly, linear term of crystallization time $\left(X_{3}\right)$ for the percentage of PUFA (LA) $\left(Y_{4}\right)$ and percentage of MUFA (LA) $\left(Y_{3}\right)$ in the concentrate were significant at $p<0.05$.

The results suggest that the linear effect of urea-toFAs ratio and crystallization time are the primary determining factors for FAs separation by urea complexation. [10] concluded that these two variables significantly influenced the results of their urea complexation study. Crystallization time was found to be the insignificant factor $(P>0.05)$. This finding is in agreement with the results reported by other researchers $[5,6,10]$.

The coefficients of independent variables (urea-to-FAs ratio; $X_{1}$, crystallization temperature; $X_{2}$ and crystallization time; $X_{3}$ ) determined for the quadratic polynomial models are given in Tables 2, 3, 4 and 5. Table 2 lists the yield\% of NUCF $\left(Y_{1}\right)$; Table 3 the percentage of SFAs (palmitic and stearic acids) $\left(Y_{2}\right)$; Table 4 the percentage of MUFA (OA) $\left(Y_{3}\right)$ and Table 5 percentage of PUFA (LA) $\left(Y_{4}\right)$ in NUCF are given below:

$$
\begin{aligned}
Y_{1}= & +27.97-16.60 X_{1}+1.85 X_{2}-1.60 X_{3} \\
& -2.39 X_{1}^{2}+3.88 X_{2}^{2}-3.43 X_{3}^{2} \\
& -2.44 X_{1} X_{2}-2.13 X_{1} X_{3}+0.69 X_{2} X_{3} \\
Y_{2}= & +0.087-0.69 X_{1}+0.40 X_{2}-0.12 X_{3} \\
& +0.92 X_{1}^{2}-0.031 X_{2}^{2}+0.72 X_{3}^{2} \\
& -0.24 X_{1} X_{2}+0.041 X_{1} X_{3}+0.26 X_{2} X_{3} \\
Y_{3}= & +18.77-14.76 X_{1}+1.04 X_{2}-1.59 X_{3} \\
& +5.19 X_{1}^{2}+0.29 X_{2}^{2}-1.32 X_{3}^{2} \\
& -0.49 X_{1} X_{2}-0.39 X_{1} X_{3}+1.08 X_{2} X_{3} \\
Y_{4}= & +80.30+16.37 X_{1}-1.30 X_{2}+1.91 X_{3} \\
& -7.14 X_{1}^{2}-0.22 X_{2}^{2}+0.65 X_{3}^{2} \\
& +0.57 X_{1} X_{2}+0.18 X_{1} X_{3}-1.10 X_{2} X_{3}
\end{aligned}
$$


Table 1 D-optimal design arrangement and responses for non-urea-complexed fraction (NUCF) of Jatropha curcas seed oil

\begin{tabular}{|c|c|c|c|c|c|c|c|c|c|}
\hline \multirow[b]{2}{*}{$\begin{array}{l}\text { Run } \\
\text { no. }\end{array}$} & \multicolumn{3}{|c|}{ Variables levels } & \multicolumn{6}{|c|}{ Responses, $Y$} \\
\hline & $\begin{array}{c}\text { Urea-FAs }{ }^{\mathrm{a}} \\
\left(X_{1}\right)\end{array}$ & $\begin{array}{c}\text { Temp. }^{b} \\
\left(X_{2}\right)\end{array}$ & $\begin{array}{c}\operatorname{Time}^{c} \\
\left(X_{3}\right)\end{array}$ & $\begin{array}{c}Y_{1}, \text { Yield } \\
(\%)\end{array}$ & $\begin{array}{c}\text { C16:0 } \\
(\%)\end{array}$ & $\begin{array}{c}\text { C18:0 } \\
(\%)\end{array}$ & $\begin{array}{c}Y_{2}, \mathrm{SFAs} \\
(\mathrm{C} 16: 0+\mathrm{C} 18: 0) \\
(\%)\end{array}$ & $\begin{array}{c}Y_{3,} \text { MUFA } \\
(\mathrm{C} 18: 1) \\
(\%)\end{array}$ & $\begin{array}{c}Y_{4}, \mathrm{LA} \\
(\mathrm{C} 18: 2) \\
(\%)\end{array}$ \\
\hline 1 & 1 & 10 & 8 & 49 & 1.44 & - & 1.44 & 36.50 & 58.23 \\
\hline 2 & 3 & 0 & 24 & 22.2 & 0.56 & 0.26 & 0.82 & 13.25 & 85.16 \\
\hline 3 & 2 & 0 & 16 & 34.9 & 0.44 & - & 0.44 & 28.87 & 69.41 \\
\hline 4 & 3 & -10 & 8 & 32.3 & 0.49 & - & 0.49 & 20.90 & 77.74 \\
\hline 5 & 5 & 10 & 24 & 7.7 & 0.43 & - & 0.43 & 9.37 & 88.60 \\
\hline 6 & 5 & -10 & 24 & 7.8 & 0.33 & - & 0.33 & 5.73 & 92.81 \\
\hline 7 & 1 & 10 & 24 & 50.6 & 3.25 & 0.30 & 3.55 & 39.67 & 54.91 \\
\hline 8 & 1 & -10 & 24 & 34.1 & 0.58 & - & 0.58 & 34.64 & 61.46 \\
\hline 9 & 5 & 10 & 8 & 8.8 & 1.23 & - & 1.23 & 9.94 & 87.82 \\
\hline 10 & 5 & 0 & 16 & 6.2 & 0.97 & - & 0.97 & 8.95 & 89.19 \\
\hline 11 & 1 & -10 & 16 & 48.1 & 1.17 & - & 1.17 & 35.55 & 59.85 \\
\hline 12 & 1 & 0 & 8 & 31.3 & 2.79 & - & 2.79 & 39.58 & 54.63 \\
\hline 13 & 5 & 10 & 24 & 4.1 & 0.94 & 0.28 & 1.23 & 6.31 & 92.14 \\
\hline 14 & 3 & 10 & 16 & 31.6 & 0.19 & - & 0.19 & 20.09 & 78.42 \\
\hline 15 & 1 & 10 & 8 & 45.6 & 3.65 & 0.33 & 3.99 & 40.49 & 52.53 \\
\hline 16 & 5 & -10 & 8 & 6.6 & 0.89 & - & 0.89 & 9.10 & 88.92 \\
\hline 17 & 5 & 0 & 8 & 20.5 & 0.34 & - & 0.34 & 10.30 & 88.12 \\
\hline 18 & 1 & 10 & 16 & 49.7 & 1.17 & - & 1.17 & 41.30 & 54.87 \\
\hline
\end{tabular}

Notes: C16:0, palmitic acid; C18:0, stearic acid; C18:1, oleic acid; C18:1, linoleic acid; SFAs, saturated fatty acids; MUFA, monounsaturated fatty acid; LA, linoleic acid;

a urea-to-FAs ratio $(\mathrm{w} / \mathrm{w})$.

${ }^{\mathrm{b}}$ crystallization temperature $\left({ }^{\circ} \mathrm{C}\right)$.

c crystallization time (h). 
Table 2 Regression coefficients of the predicted quadratic polynomial model for response variables (yield\% of NUCF) in urea inclusion fractionation experiment of $J$. curcas seed oil

\begin{tabular}{lllll}
\hline Variables & $\begin{array}{l}\text { Coefficients }(ß), \\
\text { yield \% of NUCF }\left(Y_{1}\right)\end{array}$ & \multicolumn{1}{l}{$\boldsymbol{T}$} & Notability \\
\hline Intercept & 27.97 & 11.71 & 0.0010 & $* * *$ \\
Linear & & & & \\
$X_{1}$ & -16.60 & 73.24 & 0.0001 & $* * *$ \\
$X_{2}$ & 1.85 & 0.88 & 0.3767 & \\
$X_{3}$ & -1.60 & 0.66 & 0.4405 & \\
Quadratic & & & & \\
$X_{11}$ & -2.39 & 0.31 & 0.5935 & \\
$X_{22}$ & 3.88 & 1.09 & 0.3263 & \\
$X_{33}$ & -3.43 & 0.84 & 0.3849 & \\
Interaction & & & & \\
$X_{12}$ & -2.44 & 1.28 & 0.2904 & \\
$X_{13}$ & -2.13 & 1.02 & 0.3428 & \\
$X_{23}$ & 0.69 & 0.093 & 0.7682 & \\
$R^{2}$ & 0.92 & & & \\
\hline
\end{tabular}

Notes: ** $P<0.05 ; * * *<0.01$. T: $\mathrm{F}$ test value.

See Table 1 for a description of the abbreviations.

The $F$-value for the lack-of-fit for all the responses (Table 6) showed that the lack of fit is not significant $(p>0.05)$ relative to the pure error. This indicates that all the models predicted for the responses were adequate. The regression coefficients $\left(R^{2}\right)$ of the yield\% of NUCF $\left(Y_{1}\right)$, percentage of SFAs (palmitic and stearic

Table 3 Regression coefficients of the predicted quadratic polynomial model for response variables (SFAs\%) in urea inclusion fractionation experiment of $J$. curcas seed oil

\begin{tabular}{lllll}
\hline Variables & Coefficients $(\boldsymbol{B})$, SFAs\% $\left(Y_{2}\right)$ & $\boldsymbol{T}$ & $\boldsymbol{P}$ & Notability \\
\hline Intercept & 0.087 & 1.84 & 0.2005 & \\
Linear & & & & \\
$X_{1}$ & -0.69 & 6.65 & 0.0327 & $* *$ \\
$X_{2}$ & 0.40 & 2.12 & 0.1831 & \\
$X_{3}$ & -0.12 & 0.21 & 0.6600 & \\
Quadratic & & & & \\
$X_{11}$ & 0.92 & 2.44 & 0.1572 \\
$X_{22}$ & -0.31 & 0.36 & 0.5672 \\
$X_{33}$ & 0.72 & 1.98 & 0.1972 \\
Interaction & & & \\
$X_{12}$ & -0.24 & 0.68 & 0.4342 \\
$X_{13}$ & 0.041 & 0.020 & 0.8914 \\
$X_{23}$ & 0.26 & 0.67 & 0.4370 & \\
$R^{2}$ & 0.67 & & \\
\hline
\end{tabular}

Notes: ${ }^{* *} P<0.05 ;{ }^{* * *} P<0.01 . \mathrm{T}$ : $\mathrm{F}$ test value

See Table 1 for a description of the abbreviations
Table 4 Regression coefficients of the predicted quadratic polynomial model for response variables (MUFA (OA\%)) in urea inclusion fractionation experiment of $J$. curcas seed oil

\begin{tabular}{|c|c|c|c|c|}
\hline Variables & $\begin{array}{l}\text { Coefficients }(ß), \\
\text { MUFA (OA\%) }\left(Y_{3}\right)\end{array}$ & $T$ & $P$ & Notability \\
\hline Intercept & 18.77 & 81.33 & 0.0001 & $* * *$ \\
\hline \multicolumn{5}{|l|}{ Linear } \\
\hline$x_{1}$ & -14.76 & 577.20 & 0.0001 & $* * *$ \\
\hline$x_{2}$ & 1.04 & 2.80 & 0.1330 & \\
\hline$x_{3}$ & -1.59 & 6.53 & 0.0339 & $* *$ \\
\hline \multicolumn{5}{|l|}{ Quadratic } \\
\hline$x_{11}$ & 5.19 & 14.55 & 0.0051 & $* * *$ \\
\hline$x_{22}$ & 0.29 & 0.061 & 0.8115 & \\
\hline$x_{33}$ & -1.32 & 1.25 & 0.2951 & \\
\hline \multicolumn{5}{|l|}{ Interaction } \\
\hline$x_{12}$ & -0.49 & 0.52 & 0.4906 & \\
\hline$x_{13}$ & -0.39 & 0.34 & 0.5741 & \\
\hline$x_{23}$ & 1.08 & 2.26 & 0.1714 & \\
\hline$R^{2}$ & 0.98 & & & \\
\hline
\end{tabular}

Notes: ** $P<0.05$; *** $P<0.01$. T: $F$ test value

See Table 1 for a description of the abbreviations

acids) $\left(Y_{2}\right)$, percentage of MUFA (OA) $\left(Y_{3}\right)$ and percentage of PUFA (LA) $\left(Y_{4}\right)$ in NUCF were $0.92,0.67,0.98$ and 0.99 , respectively (Table $2,3,4$ and 5 , respectively). These indicate that the generated models adequately explained the data variation and represented the actual relationships among the reaction parameters.

Table 5 Regression coefficients of the predicted quadratic polynomial model for response variables (PUFA (LA\%)) in urea inclusion fractionation experiment of $J$. curcas seed oil

\begin{tabular}{lllll}
\hline Variables & $\begin{array}{l}\text { Coefficients }(ß), \\
\text { PUFA (LA\%) }\left(Y_{4}\right)\end{array}$ & \multicolumn{1}{l}{ N } & \multicolumn{1}{l}{ Notability } \\
\hline Intercept & 80.30 & 91.62 & 0.0001 & $* * *$ \\
Linear & & & & \\
$X_{1}$ & 16.37 & 643.86 & 0.0001 & $* * *$ \\
$X_{2}$ & -1.30 & 3.95 & 0.0820 & \\
$X_{3}$ & 1.91 & 8.49 & 0.0195 & $* *$ \\
Quadratic & & & & \\
$X_{11}$ & -7.14 & 24.89 & 0.0011 & $* * *$ \\
$X_{22}$ & -0.22 & 0.032 & 0.8622 & \\
$X_{33}$ & 0.65 & 0.28 & 0.6133 & \\
Interaction & & & & \\
$X_{12}$ & 0.57 & 0.64 & 0.4466 & \\
$X_{13}$ & 0.18 & 0.065 & 0.8056 & \\
$X_{23}$ & -1.10 & 2.13 & 0.1827 & \\
$R^{2}$ & 0.99 & & & \\
\hline
\end{tabular}

Notes: ** $P<0.05 ; * * * P<0.01 . \mathrm{T}$ : $\mathrm{F}$ test value

See Table 1 for a description of the abbreviations 
Table 6 Analysis of variance (ANOVA) for all the responses of NUCF

\begin{tabular}{|c|c|c|c|c|c|c|c|}
\hline & Source & $D f$ & Sum of squares & Mean square & $F$ value & $P$ & \\
\hline \multirow[t]{4}{*}{$Y_{1}$} & Model & 3 & 4484.17 & 1494.72 & 37.83 & $<0.0001$ & Significant \\
\hline & Residual & 14 & 553.23 & 39.52 & & & \\
\hline & lack-of-fit & 12 & 540.97 & 45.08 & 7.35 & 0.1258 & Not significant \\
\hline & Pure error & 2 & 12.26 & 6.13 & & & \\
\hline \multirow[t]{4}{*}{$Y_{2}$} & Model & 3 & 8.44 & 2.81 & 3.20 & 0.0560 & Not significant \\
\hline & Residual & 14 & 12.29 & 0.88 & & & \\
\hline & lack-of-fit & 12 & 8.73 & 0.73 & 0.41 & 0.8720 & Not significant \\
\hline & Pure error & 2 & 3.57 & 1.78 & & & \\
\hline \multirow[t]{4}{*}{$Y_{3}$} & Model & 9 & 3259.79 & 362.20 & 81.33 & $<0.0001$ & Significant \\
\hline & Residual & 8 & 35.63 & 4.45 & & & \\
\hline & lack-of-fit & 6 & 23.03 & 3.84 & 0.61 & 0.7298 & Not significant \\
\hline & Pure error & 2 & 12.59 & 6.30 & & & \\
\hline \multirow[t]{4}{*}{$Y_{4}$} & Model & 9 & 4051.33 & 450.15 & 91.62 & $<0.0001$ & Significant \\
\hline & Residual & 8 & 39.31 & 4.91 & & & \\
\hline & lack-of-fit & 6 & 16.80 & 2.80 & 0.25 & 0.9219 & Not significant \\
\hline & Pure error & 2 & 22.50 & 11.25 & & & \\
\hline
\end{tabular}

Equations 1, 2, 3 and 4 showed that the yield\% of NUCF $\left(Y_{1}\right)$, percentage of SFAs (palmitic and stearic acids) $\left(Y_{2}\right)$, percentage of MUFA (OA) $\left(Y_{3}\right)$ and percentage of PUFA (LA) $\left(Y_{4}\right)$ in NUCF have a complex relationship with independent variables that encompass both first- and second-order polynomials. The relationships between independent and dependent variables are shown in the three-dimensional representation as response surfaces. The response surfaces for the yield\% of NUCF $\left(Y_{1}\right)$, percentage of SFAs (palmitic and stearic acids) $\left(Y_{2}\right)$, percentage of MUFA (OA) $\left(Y_{3}\right)$ and percentage of PUFA (LA) $\left(Y_{4}\right)$ in NUCF in the concentrates are given in Figures 1, 2, 3 and 4, respectively. The contour plots (Figures 1b, 2b, 3b and $4 b$ ) show the combination of levels of the urea-to-FAs ratio that can afford the same level of the yield\% of NUCF $\left(Y_{1}\right)$, percentage of SFAs (palmitic and stearic acids) $\left(Y_{2}\right)$, percentage of MUFA (OA) $\left(Y_{3}\right)$ and percentage of PUFA (LA) $\left(Y_{4}\right)$ in NUCF.

Figures 1, 2, 3 and 4 show increasing amount of urea and decreasing crystallization temperature which led to reduction of percentage of SFAs and MUFA (OA) in liquid NUCF. The content of PUFA (LA) in the liquid fraction would also be enriched under these conditions (Figure 4). The relationships between the parameters and FAs percentages were linear or almost linear. High concentration of PUFA (LA) could be obtained by using high ratio of urea-to-FAs at low temperatures. However, this could also reduce the yield\% of liquid NUCF in the final product as more LA would be lost into urea adducts. Experimental variables should therefore be carefully controlled in order to recover a maximum content of PUFA (LA) of interest with reasonable yield\% [5].

Straight-chained molecules such as SFAs readily formed stable adduct with urea. SFAs formed complexes more readily than MUFA. MUFA formed more readily inclusion compounds than PUFA (LA). Similar complexation tendency patterns were also obtained by [12]. The addition of more urea could reduce the SFAs percentage in NUCF to a minimum level; it however results in indiscriminate FAs complexation and thus reducing the amount of MUFA (OA) and PUFA (LA). A lower urea-to-FAs ratio prevented indiscriminate FAs complexation. Lower crystallization temperature can facilitate formation of more stable urea adducts, that would reduce SFAs in NUCF. Longer periods of crystallization time would allow the crystals to further stabilize. However the parameters must be set at a level to achieve an acceptable yield $\%$ of product with high purity. Higher purity of PUFA (LA) will always give lower yield of NUCF.

Optimum conditions using D-optimal design to obtain maximum concentration of PUFA (LA) and minimum concentration of both SFAs (palmitic and stearic acids) and MUFA (OA) were predicted at a urea-to-FAs ratio $(\mathrm{w} / \mathrm{w})$ of $5: 1$, crystallization temperature of $-10^{\circ} \mathrm{C}$ and $24 \mathrm{~h}$ of crystallization time. The final NUCF was predicted to contain $0.33 \%$ of SFAs (palmitic and stearic acids), $5.73 \%$ of MUFA (OA) and $92.81 \%$ of PUFA (LA) with the NUCF yield of $7.8 \%$. The observed value was reasonably close to the predicted value as shown in Figures 5, 6, 7 and 8 . 

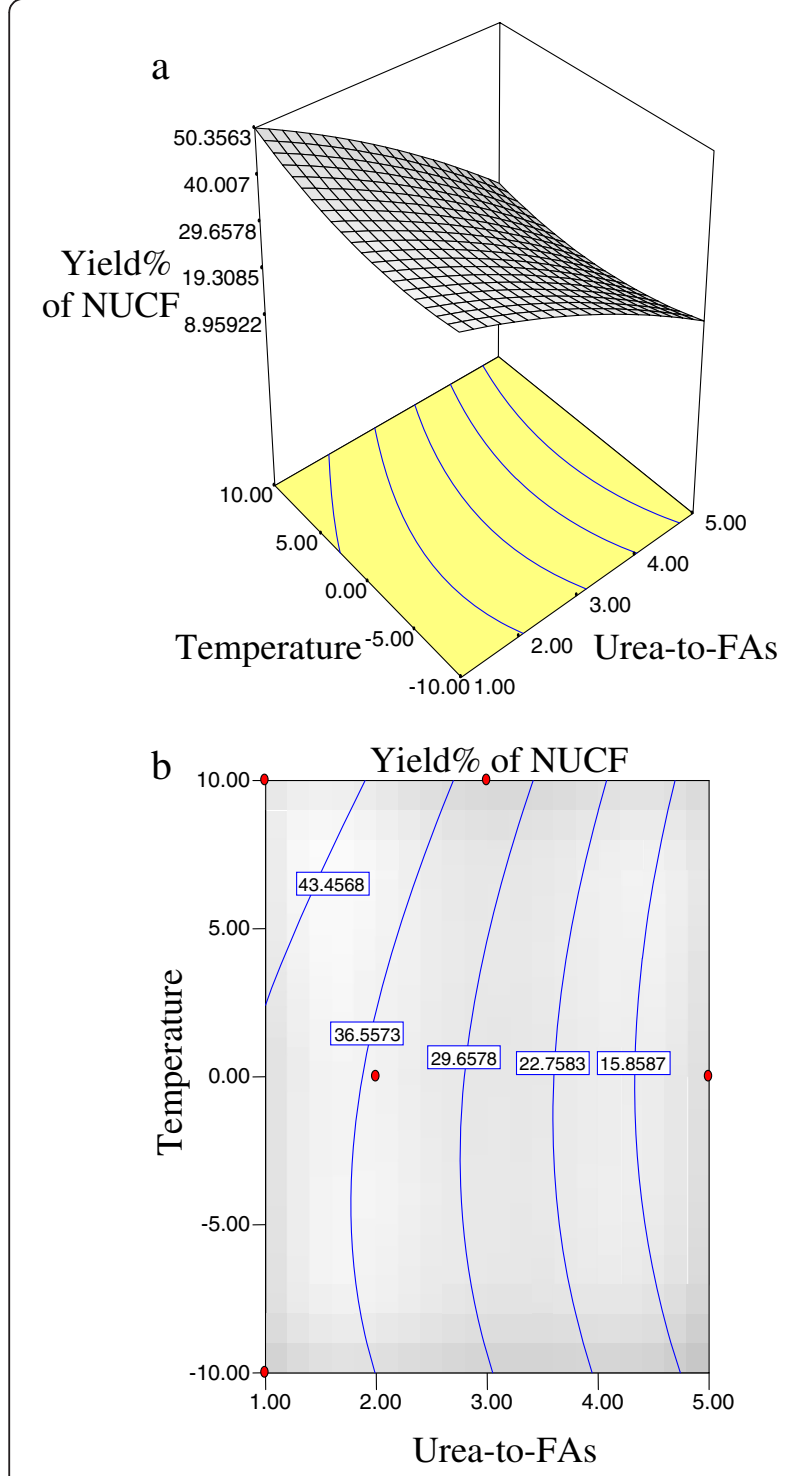

Figure 1 Response surface (a) and contour plots (b) for the effect of the urea-to-FAs ratio $\left(X_{1}, \mathrm{w} / \mathrm{w}\right)$ and crystallization temperature $\left(X_{2},{ }^{\circ} \mathrm{C}\right)$ on the yield\% $\left(Y_{1}\right)$ of NUCF.

\section{Urea complex fraction (UCF)}

The crystallization process with urea complex fraction (UCF) selects SFAs (palmitic and stearic acids) and MUFA (OA), simultaneously maintain the highest yield\% of SFAs and MUFA (OA). The new tendency of FAs to combine with urea decreases with increasing UFAs [9]. Table 7 shows the FAs composition in the UCF. The SFAs and MUFA (OA) percentage were significantly higher compared to the starting material while PUFA (LA) was lower in all the samples. The highest percentage of SFAs (44.27\%) was observed for sample treated with 1:1 urea-to-FAs ratio $(\mathrm{w} / \mathrm{w})$ at $10^{\circ} \mathrm{C}$ for $16 \mathrm{~h}$.

The highest percentage of MUFA (OA) (56.01\%) was observed for samples treated with 3:1 urea-to-FAs ratio

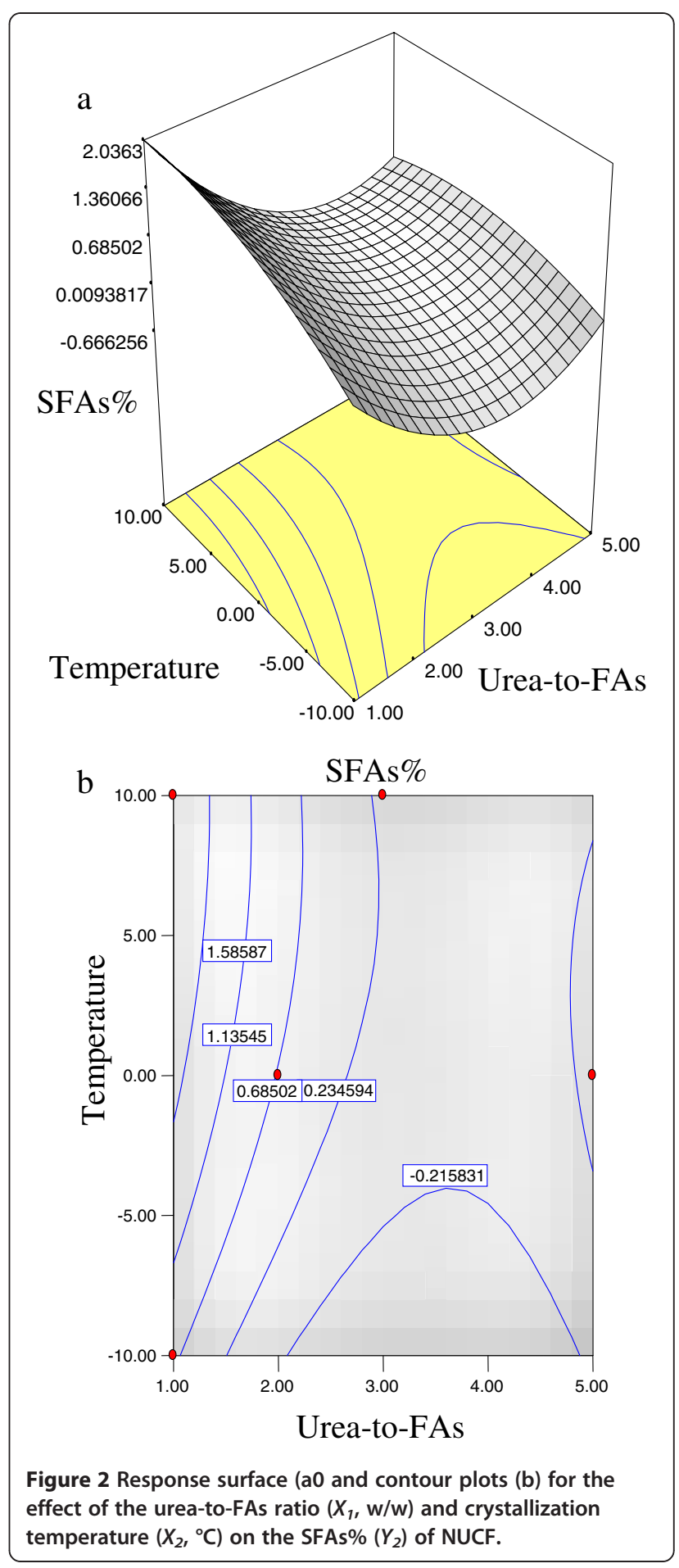

$(\mathrm{w} / \mathrm{w})$ at $10^{\circ} \mathrm{C}$ for $16 \mathrm{~h}$, while the lowest percentage of PUFA (LA) (8.13\%) was incorporated into the urea complex with 1:1 urea-to-FAs ratio $(\mathrm{w} / \mathrm{w})$ at $10^{\circ} \mathrm{C}$ for $8 \mathrm{~h}$. Inclusion of more PUFA (LA) into UCF reduced the percentage of SFAs and MUFA (OA) in the samples. The process may be not suitable for industrial uses because this method cannot 

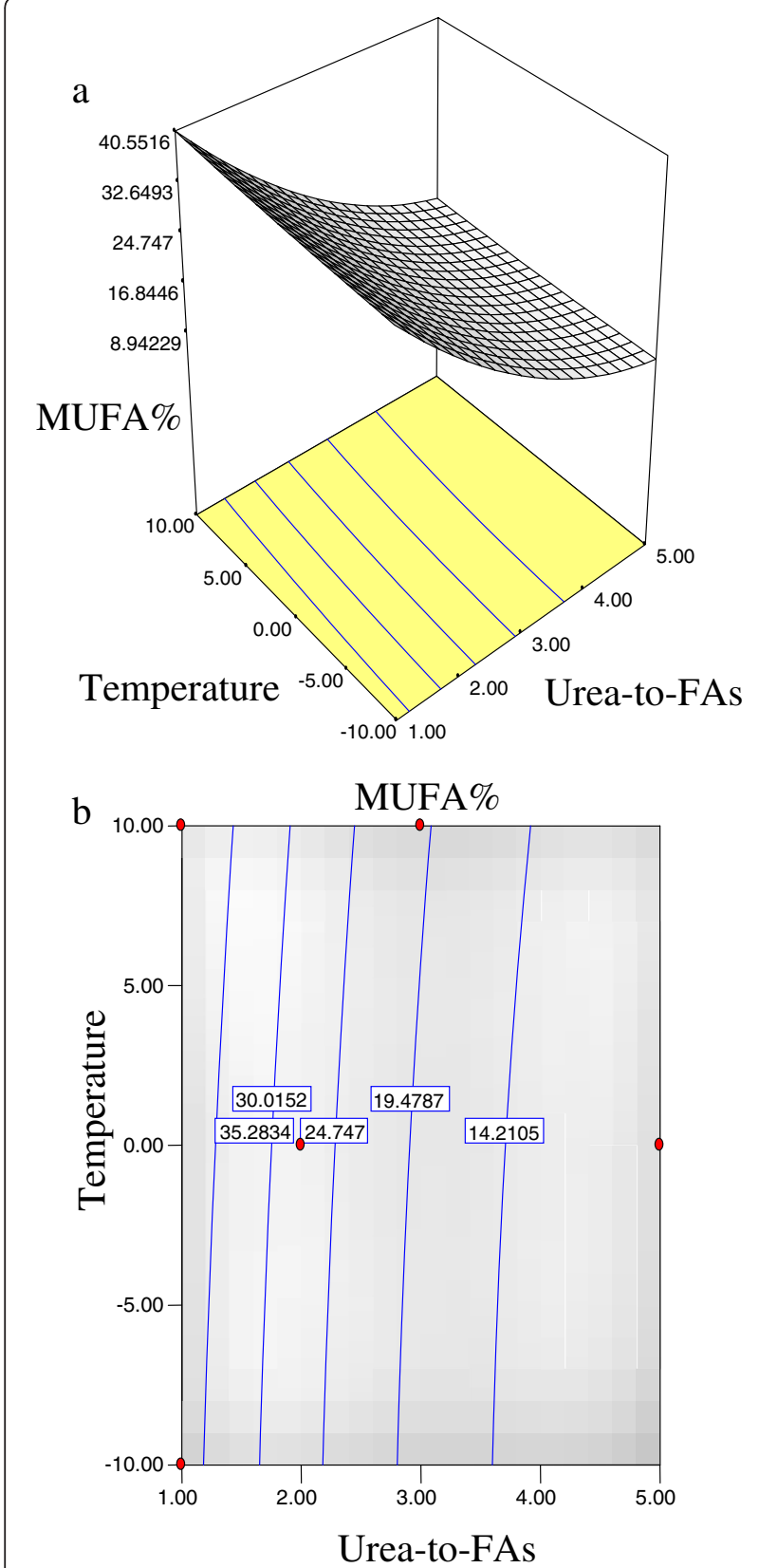

Figure 3 Response surface (a) and contour plots (b) for the effect of the urea-to-FAs ratio $\left(X_{1}, \mathrm{w} / \mathrm{w}\right)$ and crystallization temperature $\left(X_{2},{ }^{\circ} \mathrm{C}\right)$ on the MUFA (OA\%) $\left(Y_{3}\right)$ of NUCF.

employ high purity SFAs (palmitic and stearic acids) and MUFA (OA).

The quadratic regression coefficient obtained by employing a least squares method to predict quadratic polynomial models for the yield\% of solid UCF $\left(Y_{5}\right)$, percentage SFAs (palmitic and stearic acids) $\left(Y_{6}\right)$, percentage MUFA (OA) $\left(Y_{7}\right)$ and percentage PUFA (LA) $\left(Y_{8}\right)$ are given in Tables 8, 9, 10 and 11 respectively.

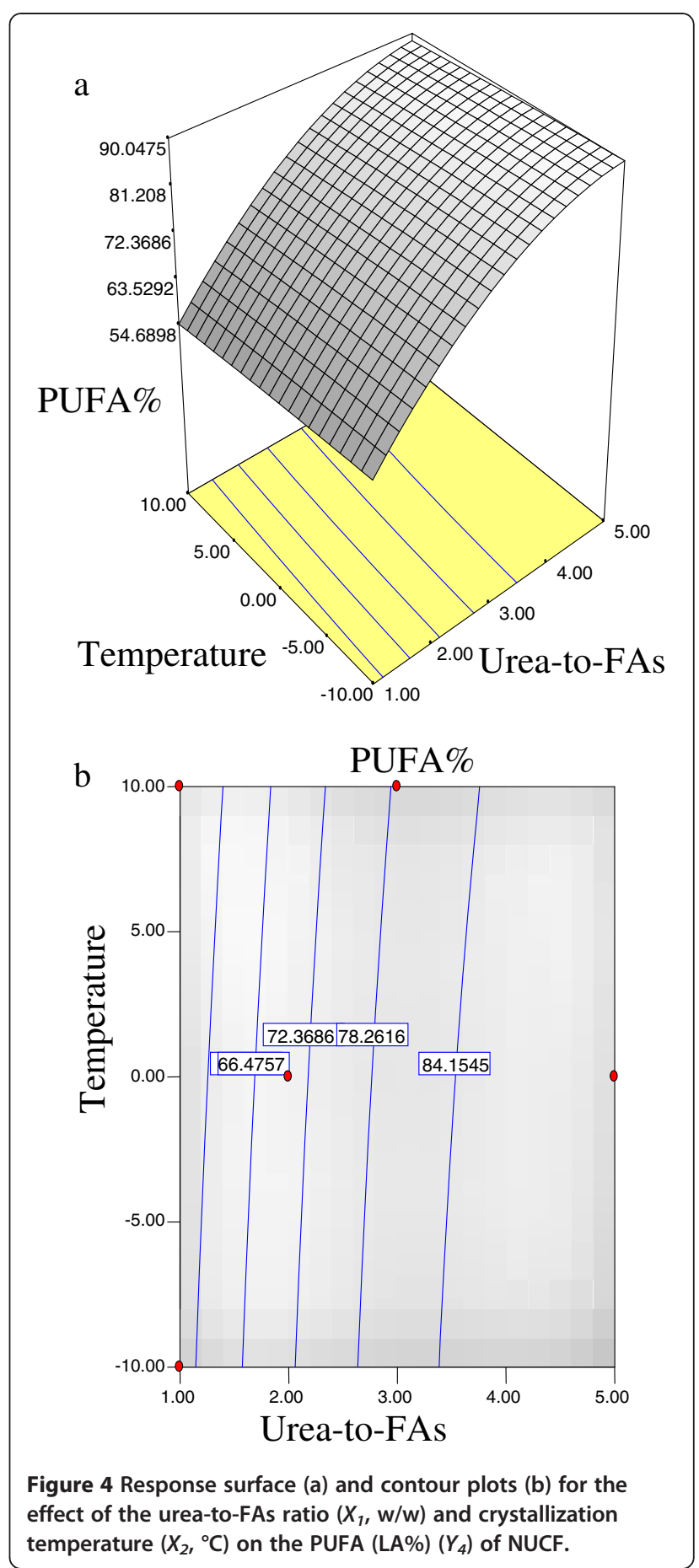

Linear term of urea-to-FAs ratio was highly significant $(p<0.01)$ for the yield\% of UCF $\left(Y_{5}\right)$ and percentage SFAs $\left(Y_{6}\right)$, while the linear term of urea-to-FAs was significant $(P<0.05)$ for the percentage PUFA (LA) $\left(Y_{8}\right)$. The interaction between urea-to-FAs ratio and crystallization temperature were significant $(p<0.05)$ for the percentage PUFA (LA) $\left(Y_{8}\right)$ and the percentage SFAs $\left(Y_{6}\right)$. Quadratic term of urea-to-FAs ratio was 

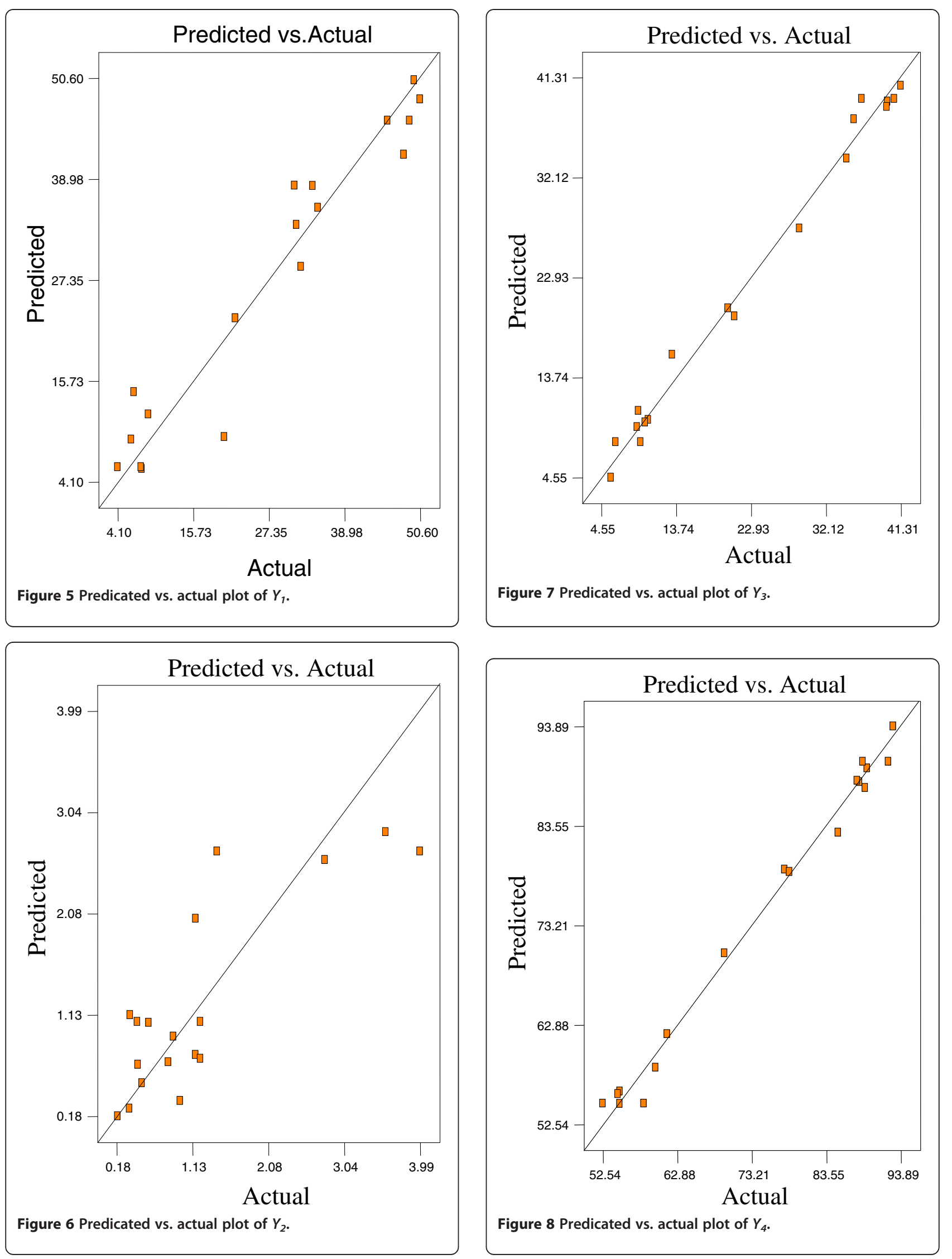
Table 7 D-optimal design arrangement and responses for urea-complexed fraction (UCF) of Jatropha curcas seed oil

\begin{tabular}{|c|c|c|c|c|c|c|c|c|c|}
\hline \multirow[b]{2}{*}{$\begin{array}{l}\text { Run } \\
\text { no. }\end{array}$} & \multicolumn{3}{|c|}{ Variables levels } & \multicolumn{6}{|c|}{ Responses, $Y$} \\
\hline & $\begin{array}{c}\text { Urea-FAs }^{\mathrm{a}} \\
\left(X_{1}\right)\end{array}$ & $\begin{array}{c}\text { Temp. }^{\text {b }} \\
\left(X_{2}\right)\end{array}$ & $\begin{array}{c}\operatorname{Time}^{c} \\
\left(X_{3}\right)\end{array}$ & $\begin{array}{c}Y_{5}, \text { Yield } \\
\text { (\%) }\end{array}$ & $\begin{array}{c}\text { C16:0 } \\
(\%)\end{array}$ & $\begin{array}{c}\text { C18:0 } \\
(\%)\end{array}$ & $\begin{array}{c}Y_{6}, \text { SFAs } \\
(\mathrm{C} 16: 0+\mathrm{C} 18: 0) \\
(\%)\end{array}$ & $\begin{array}{c}Y_{7, M U F A} \\
(\text { C18:1) } \\
(\%)\end{array}$ & $\begin{array}{c}Y_{8,} \text { LA } \\
\text { (C18:2) } \\
\text { (\%) }\end{array}$ \\
\hline 1 & 1 & 10 & 8 & 50.7 & 25.42 & 13.97 & 39.39 & 48.10 & 8.13 \\
\hline 2 & 3 & 0 & 24 & 78.6 & 17.09 & 9.27 & 26.36 & 53.15 & 19.94 \\
\hline 3 & 2 & 0 & 16 & 64.9 & 22.62 & 21.50 & 44.13 & 44.89 & 10.23 \\
\hline 4 & 3 & -10 & 8 & 67.4 & 19.34 & 10.28 & 29.62 & 54.11 & 15.47 \\
\hline 5 & 5 & 10 & 24 & 92.1 & 14.14 & 7.36 & 21.50 & 45.07 & 29.34 \\
\hline 6 & 5 & -10 & 24 & 92.0 & 20.59 & 12.43 & 33.02 & 55.41 & 8.37 \\
\hline 7 & 1 & 10 & 24 & 48.7 & 25.06 & 14.57 & 39.64 & 45.69 & 11.50 \\
\hline 8 & 1 & -10 & 24 & 65.7 & 23.06 & 12.24 & 35.31 & 45.63 & 15.74 \\
\hline 9 & 5 & 10 & 8 & 91.0 & 13.52 & 8.11 & 21.63 & 42.61 & 31.45 \\
\hline 10 & 5 & 0 & 16 & 93.5 & 14.47 & 8.91 & 23.39 & 44.44 & 28.68 \\
\hline 11 & 1 & -10 & 16 & 51.3 & 19.76 & 10.39 & 30.16 & 45.28 & 20.83 \\
\hline 12 & 1 & 0 & 8 & 68.8 & 20.37 & 11.84 & 32.21 & 43.89 & 20.10 \\
\hline 13 & 5 & 10 & 24 & 95.7 & 13.40 & 6.52 & 19.92 & 42.38 & 35.81 \\
\hline 14 & 3 & 10 & 16 & 68.3 & 20.37 & 11.08 & 31.46 & 56.01 & 12.10 \\
\hline 15 & 1 & 10 & 8 & 54.3 & 23.34 & 13.49 & 36.84 & 45.28 & 14.61 \\
\hline 16 & 5 & -10 & 8 & 93.2 & 13.68 & 8.33 & 22.01 & 42.89 & 30.77 \\
\hline 17 & 5 & 0 & 8 & 79.2 & 16.61 & 8.94 & 25.56 & 53.00 & 20.87 \\
\hline 18 & 1 & 10 & 16 & 49.8 & 28.38 & 15.89 & 44.27 & 43.04 & 9.46 \\
\hline
\end{tabular}

Notes: C16:0, palmitic acid; C18:0, stearic acid; C18:1, oleic acid; C18:2, linoleic acid; SFAs, saturated fatty acids; MUFA, monounsaturated fatty acid; LA, linoleic acid;

${ }^{a}$ urea-to-FAs ratio $(\mathrm{w} / \mathrm{w})$.

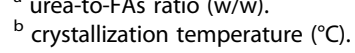

c crystallization time (h). 
Table 8 Regression coefficients of the predicted quadratic polynomial model for response variables (yield\% of UCF) in urea inclusion fractionation experiment of $J$. curcas seed oil

\begin{tabular}{lllll}
\hline Variables & $\begin{array}{l}\text { Coefficients }(ß), \\
\text { yield \% of UCF }\left(Y_{5}\right)\end{array}$ & \multicolumn{1}{l}{ N } & $P$ & Notability \\
\hline Intercept & 72.14 & 11.29 & 0.0012 & $* * *$ \\
Linear & & & & \\
$X_{1}$ & 16.64 & 70.27 & 0.0001 & $* * *$ \\
$X_{2}$ & -1.83 & 0.82 & 0.3911 & \\
$X_{3}$ & 1.65 & 0.67 & 0.4370 & \\
Quadratic & & & & \\
$X_{11}$ & 1.97 & 0.20 & 0.6662 & \\
$X_{22}$ & -4.18 & 1.21 & 0.3038 & \\
$X_{33}$ & 3.74 & 0.96 & 0.3568 & \\
Interaction & & & & \\
$X_{12}$ & 2.46 & 1.25 & 0.2965 & \\
$X_{13}$ & 2.21 & 1.04 & 0.3374 & \\
$X_{23}$ & -0.81 & 0.12 & 0.7362 & \\
$R^{2}$ & 0.92 & & & \\
\hline
\end{tabular}

Notes: ${ }^{*} P<0.05$; ${ }^{* *} P<0.01$. T: $\mathrm{F}$ test value.

See Table 7 for a description of the abbreviations.

also significant $(p<0.05)$ for the percentage MUFA $(\mathrm{OA})\left(Y_{7}\right)$

The coefficients of the independent variables (urea-toFAs ratio; $X_{1}$, crystallization temperature; $X_{2}$ and crystallization time; $X_{3}$ ) determined for the quadratic polynomial models are lists in Tables 8, 9, 10 and 11 respectively. Table 8 lists the yield\% of solid UCF $\left(Y_{5}\right)$,

Table 9 Regression coefficients of the predicted quadratic polynomial model for response variables (SFAs\%) in urea inclusion fractionation experiment of $J$. curcas seed oil

\begin{tabular}{lllll}
\hline Variables & $\begin{array}{l}\text { Coefficients } \\
(\beta), \text { SFA\% }\left(Y_{6}\right)\end{array}$ & $T$ & $P$ & Notability \\
\hline Intercept & 33.80 & 4.51 & 0.0226 & ${ }^{* *}$ \\
Linear & & & & \\
$X_{1}$ & -5.43 & 16.17 & 0.0038 & $* * *$ \\
$X_{2}$ & 0.38 & 0.076 & 0.7898 & \\
$X_{3}$ & 1.49 & 1.17 & 0.3101 & \\
Quadratic & & & & \\
$X_{11}$ & -1.22 & 0.17 & 0.6943 & \\
$X_{22}$ & -0.053 & $4.140 \mathrm{E}-004$ & 0.9843 & \\
$X_{33}$ & -3.06 & 1.39 & 0.2719 & \\
Interaction & & & & \\
$X_{12}$ & -3.96 & 6.99 & 0.0295 & $*$ \\
$X_{13}$ & -0.41 & 0.078 & 0.7868 & \\
$X_{23}$ & -1.78 & 1.28 & 0.2913 & \\
$R^{2}$ & 0.83 & & & \\
\hline
\end{tabular}

Notes: ** $P<0.05 ; * * * 0.01$. T: $\mathrm{F}$ test value.

See Table 7 for a description of the abbreviations.
Table 10 Regression coefficients of the predicted quadratic polynomial model for response variables (MUFA (OA\%)) in urea inclusion fractionation experiment of $J$. curcas seed oil

\begin{tabular}{lllll}
\hline Variables & $\begin{array}{l}\text { Coefficients }\left(\boldsymbol{B}_{\mathbf{1}},\right. \\
\text { MUFA }(\mathbf{O A} \%)\left(Y_{\boldsymbol{7}}\right)\end{array}$ & $\boldsymbol{T}$ & $\boldsymbol{P}$ & Notability \\
\hline Intercept & 52.35 & 1.43 & 0.3118 & \\
Linear & & & & \\
$X_{1}$ & 1.40 & 1.26 & 0.2940 & \\
$X_{2}$ & -1.07 & 0.72 & 0.4218 & \\
$X_{3}$ & 0.78 & 0.38 & 0.5571 & \\
Quadratic & & & & \\
$X_{11}$ & -8.33 & 9.08 & 0.0167 & $* *$ \\
$X_{22}$ & 0.71 & 0.089 & 0.7728 & \\
$X_{33}$ & 1.58 & 0.43 & 0.5281 & \\
Interaction & & & & \\
$X_{12}$ & -1.68 & 1.47 & 0.2604 & \\
$X_{13}$ & 0.39 & 0.082 & 0.7821 & \\
$X_{23}$ & -1.89 & 1.68 & 0.2315 & \\
$R^{2}$ & 0.61 & & & \\
\hline
\end{tabular}

Notes: ** $P<0.05 ; * * * 0.01$. T: $F$ test value.

See Table 7 for a description of the abbreviations.

Table 9 lists the percentage SFAs (palmitic and stearic acids) $\left(Y_{6}\right)$, Table 10 lists the percentage MUFA (OA) $\left(Y_{7}\right)$ and Table 11 lists the percentage PUFA (LA) $\left(Y_{8}\right)$.

The fitted models for ANOVA are summarized in Table 12. Examinations of the two models with an F-test

Table 11 Regression coefficients of the predicted quadratic polynomial model for response variables (PUFA (LA\%)) in urea inclusion fractionation experiment of J. curcas seed oil

\begin{tabular}{lllll}
\hline Variables & $\begin{array}{l}\text { Coefficients }(\boldsymbol{B}), \\
\text { PUFA (LA\%) }\left(Y_{8}\right)\end{array}$ & $\boldsymbol{T}$ & $\boldsymbol{P}$ & Notability \\
\hline Intercept & 13.73 & 3.77 & 0.0375 & $* *$ \\
Linear & & & & \\
$X_{1}$ & 4.16 & 6.42 & 0.0350 & $* *$ \\
$X_{2}$ & 0.83 & 0.25 & 0.6321 & \\
$X_{3}$ & -2.07 & 1.54 & 0.2500 & \\
Quadratic & & & & \\
$X_{11}$ & 6.88 & 3.59 & 0.0949 & \\
$X_{22}$ & -1.44 & 0.21 & 0.6592 & \\
$X_{33}$ & 1.55 & 0.24 & 0.6360 & \\
Interaction & & & & \\
$X_{12}$ & 5.61 & 9.49 & 0.0151 & $* *$ \\
$X_{13}$ & -0.15 & $6.701 \mathrm{E}-003$ & 0.9368 & \\
$X_{23}$ & 3.74 & 3.79 & 0.0874 & \\
$R^{2}$ & 0.80 & & & \\
\hline
\end{tabular}

Notes: $* * 0<0.05 ; * * *<0.01$. T: $F$ test value. See Table 7 for a description of the abbreviations. 
Table 12 Analysis of variance (ANOVA) for all the responses of UCF

\begin{tabular}{|c|c|c|c|c|c|c|c|}
\hline & Source & $D f$ & Sum of squares & Mean square & $F$ value & $P$ & \\
\hline \multirow[t]{4}{*}{$Y_{5}$} & Model & 3 & 4510.49 & 1503.50 & 35.98 & $<0.0001$ & Significant \\
\hline & Residual & 14 & 484.99 & 41.79 & & & \\
\hline & lack-of-fit & 12 & 572.03 & 47.67 & 7.36 & 0.1258 & Not significant \\
\hline & Pure error & 2 & 12.96 & 6.48 & & & \\
\hline \multirow[t]{4}{*}{$Y_{6}$} & Model & 3 & 671.30 & 223.77 & 8.39 & 0.0019 & Significant \\
\hline & Residual & 14 & 373.55 & 26.68 & & & \\
\hline & lack-of-fit & 12 & 369.04 & 30.75 & 13.65 & 0.0702 & Not significant \\
\hline & Pure error & 2 & 4.50 & 2.25 & & & \\
\hline \multirow[t]{4}{*}{$Y_{7}$} & Model & 9 & 236.43 & 26.27 & 1.43 & 0.3118 & Not significant \\
\hline & Residual & 8 & 146.77 & 18.35 & & & \\
\hline & lack-of-fit & 6 & 139.17 & 23.19 & 6.10 & 0.1475 & Not significant \\
\hline & Pure error & 2 & 7.60 & 3.80 & & & \\
\hline \multirow[t]{4}{*}{$Y_{8}$} & Model & 6 & 940.28 & 156.71 & 4.42 & 0.0163 & Significant \\
\hline & Residual & 11 & 390.43 & 35.49 & & & \\
\hline & lack-of-fit & 9 & 348.48 & 38.72 & 1.85 & 0.4004 & Not significant \\
\hline & Pure error & 2 & 41.95 & 20.98 & & & \\
\hline
\end{tabular}

and T-test indicate a non-significant lack-of-fit at $p>0.05$. The regression coefficients $\left(R^{2}\right)$ of the yield\% of solid UCF $\left(Y_{5}\right)$, percentage SFAs (palmitic and stearic acids) $\left(Y_{6}\right)$, percentage MUFA (OA) $\left(Y_{7}\right)$ and percentage PUFA (LA) $\left(Y_{8}\right)$ were $0.92,0.83,0.61$ and 0.80 , respectively.

Equations 5, 6, 7 and 8 showed that the yield\% of solid $\operatorname{UCF}\left(Y_{5}\right)$, percentage SFAs (palmitic and stearic acids) $\left(Y_{6}\right)$, percentage MUFA $(\mathrm{OA})\left(Y_{7}\right)$ and percentage PUFA (LA) $\left(Y_{8}\right)$ in UCF have a complex relationship with independent variables that encompass both first- and second-order polynomials.

$$
\begin{aligned}
Y_{5}= & +72.14+16.64 X_{1}-1.83 X_{2}+1.65 X_{3} \\
& +1.97 X_{1}^{2}-4.18 X_{2}^{2}+3.74 X_{3}^{2} \\
& +2.46 X_{1} X_{2}+2.21 X_{1} X_{3}-0.81 X_{2} X_{3} \\
Y_{6}= & +33.80-5.43 X_{1}+0.38 X_{2}+1.49 X_{3} \\
& -1.22 X_{1}^{2}-0.035 X_{2}^{2}-3.06 X_{3}^{2} \\
& -3.96 X_{1} X_{2}-0.41 X_{1} X_{3}-1.78 X_{2} X_{3} \\
Y_{7}= & +52.35-14.76 X_{1}-1.07 X_{2}+0.78 X_{3} \\
& -8.33 X_{1}^{2}+0.71 X_{2}^{2}+1.58 X_{3}^{2} \\
& -1.68 X_{1} X_{2}+0.39 X_{1} X_{3}+0.39 X_{2} X_{3} \\
Y_{8}= & +13.73+4.16 X_{1}+0.83 X_{2}-2.07 X_{3} \\
& +6.88 X_{1}{ }^{2}-1.44 X_{2}{ }^{2}+1.55 X_{3}^{2} \\
& +5.61 X_{1} X_{2}-0.15 X_{1} X_{3}+3.74 X_{2} X_{3}
\end{aligned}
$$

The response surfaces for the yield\% of solid UCF $\left(Y_{5}\right)$, percentage SFAs (palmitic and stearic acids) $\left(Y_{6}\right)$, percentage MUFA (OA) $\left(Y_{7}\right)$ and percentage PUFA (LA)
$\left(Y_{8}\right)$ in the concentrates are given in Figures 9, 10, 11 and 12, respectively. The contour plots (Figures 9b, 10b, $11 \mathrm{~b}$ and 12b) show the combination of levels of the urea-to-FAs ratio that can afford the same level of the yield\% of solid UCF $\left(Y_{5}\right)$, percentage SFAs (palmitic and stearic acids) $\left(Y_{6}\right)$, percentage MUFA (OA) $\left(Y_{7}\right)$ and percentage PUFA (LA) $\left(Y_{8}\right)$.

Figures 9, 10, 11 and 12 also represent the DesignExpert plots for all the responses. In the solid UCF, performing the technique using low amount of urea without cooling would give the desired high percentage of SFAs and MUFA (OA) as shown in Figures 10 and 11, respectively. PUFA (LA\%) (Figure 12) was lower under these conditions. The observed value was reasonably close to the predicted value as shown in Figures 13, 14, 15 and 16.

\section{Conclusion}

Optimum conditions of the experiment to obtain maximum concentration of PUFA (LA), were predicted at urea-to-FAs ratio (w/w) of 5:1, crystallization temperature of $-10^{\circ} \mathrm{C}$ and $24 \mathrm{~h}$ of crystallization time. The final NUCF At this condition was predicted to contain $92.81 \%$ of PUFA (LA) with a NUCF yield of $7.8 \%$. The highest percentage MUFA (OA) (56.01\%) was observed for sample treated with a urea-to-FAs ratio $(\mathrm{w} / \mathrm{w})$ of $3: 1$ at $10^{\circ} \mathrm{C}$ for $16 \mathrm{~h}$. The lowest percentage PUFA (LA) (8.13\%) was incorporated into the UCF with a urea-to-FAs ratio (w/w) of $1: 1$ at $10^{\circ} \mathrm{C}$ for $8 \mathrm{~h}$. All of the above mentioned factors have to be controlled to yield a reasonable amount of product with a desirable purity of FAs. 


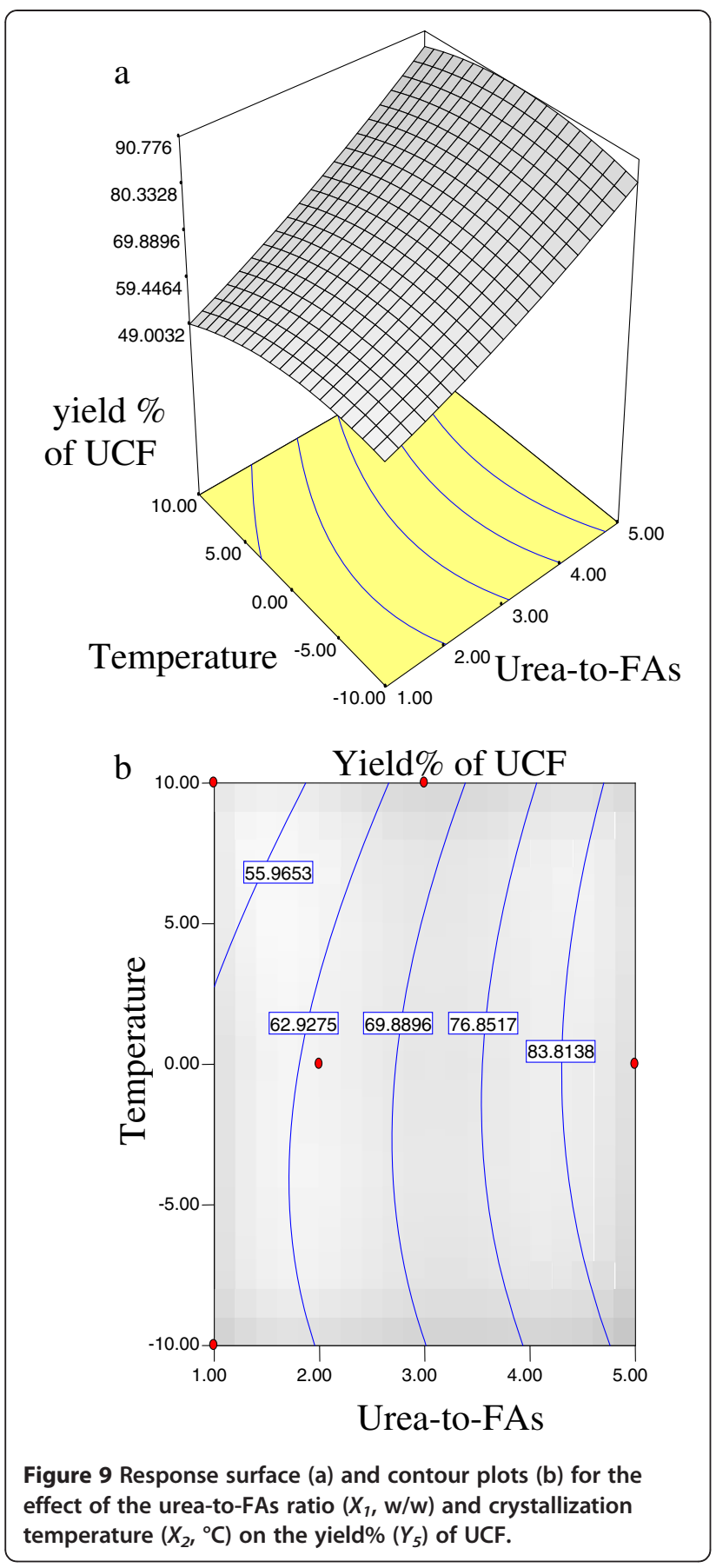

\section{Experimental and Methods}

\section{Experimental and Methods}

FAs were obtained by the hydrolysis of J. curcas seed oil, as carried out by [13]. The separation of PUFA from the hydrolyzed FAs of $J$. curcas seed oil was carried out using the technique describe by [5]. FAs of J. curcas seed oil $(10 \mathrm{~g})$ were mixed with urea in $95 \%$ aqueous ethanol and heated at $60^{\circ} \mathrm{C}$ with stirring until the mixture turned into a clear homogeneous solution. The ratio of urea-to-
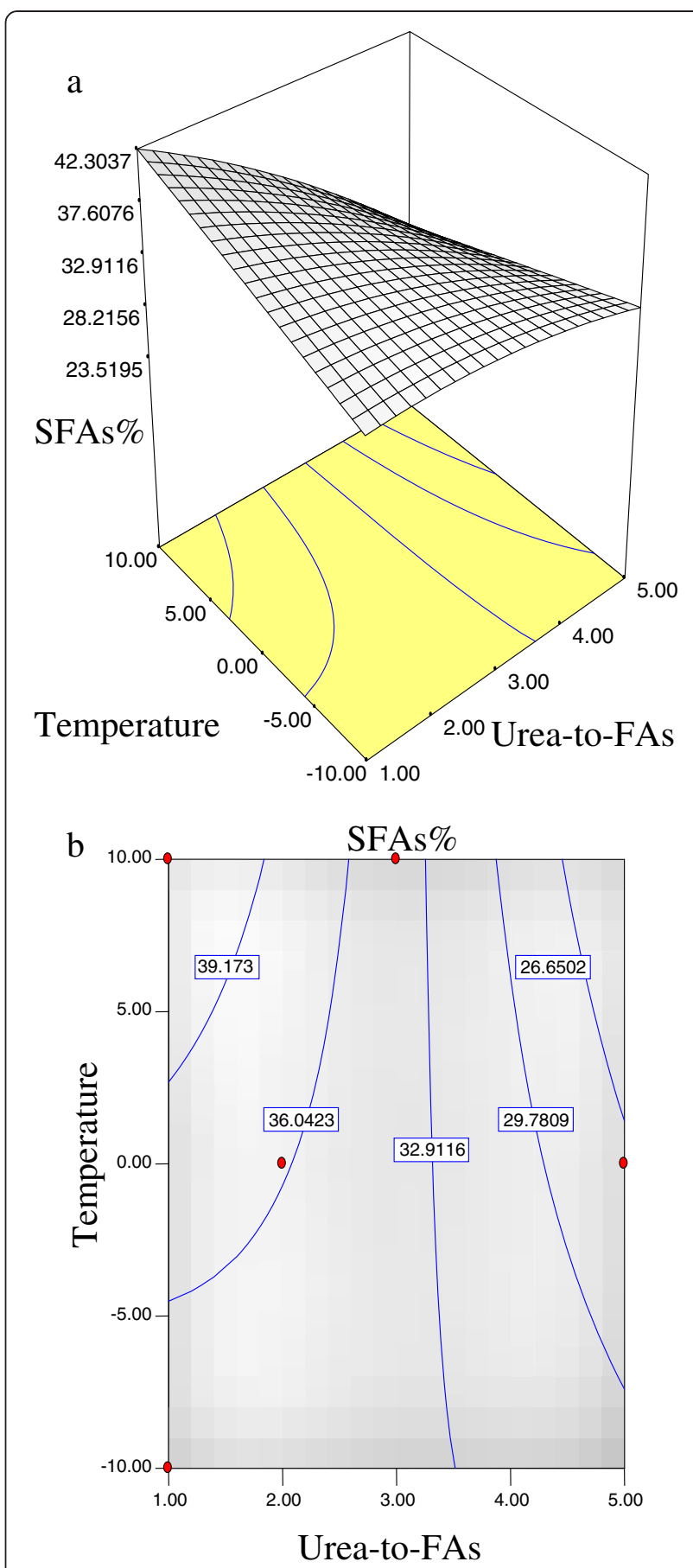

Figure 10 Response surface (a) and contour plots (b) for the effect of the urea-to-FAs ratio $\left(X_{1}, \mathrm{w} / \mathrm{w}\right)$ and crystallization temperature $\left(X_{2},{ }^{\circ} \mathrm{C}\right)$ on the SFAs\% $\left(Y_{6}\right)$ of UCF.

FAs (Table 13) was changed by using different amounts of urea (1-5 g). Initially, the urea-FAs adduct was allowed to crystallize at room temperature but lower temperatures were maintained for different periods to allow further crystallization. The crystals formed (UCF) 

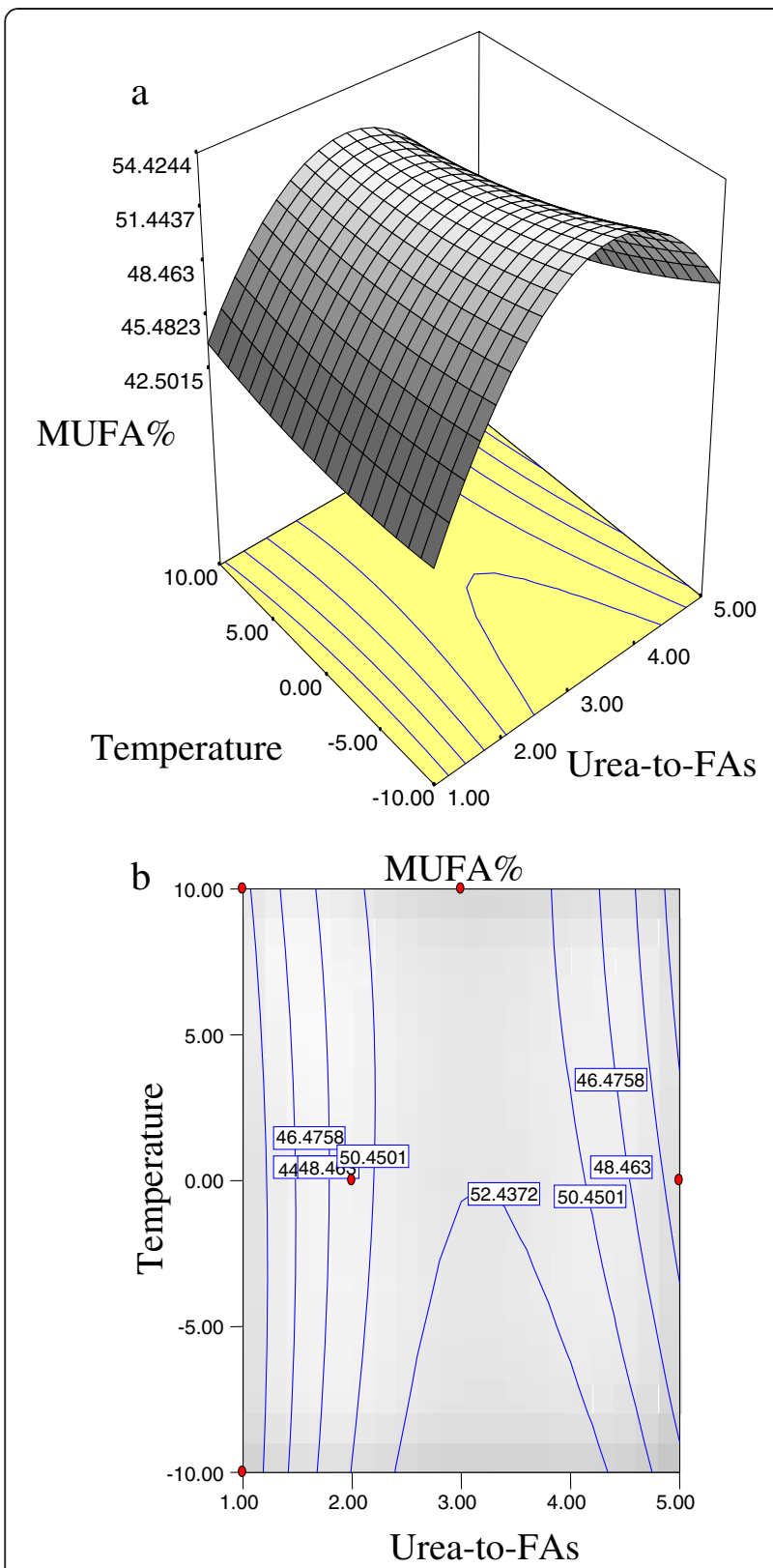

Figure 11 Response surface (a) and contour plots (b) for the effect of the urea-to-FAs ratio $\left(X_{1}, \mathrm{w} / \mathrm{w}\right)$ and crystallization temperature $\left(X_{2},{ }^{\circ} \mathrm{C}\right)$ on the MUFA\% $(\mathrm{OA})\left(Y_{7}\right)$ of UCF.

were separated from the liquid (NUCF) by fast filtration. The liquid (NUCF) was diluted with an equal volume of water and acidified to $\mathrm{pH} 2-3$ with $6 \mathrm{~N} \mathrm{HCl}$; an equal volume of petroleum ether was subsequently added and the FAs were extracted. The non-aqueous phase (top phase), containing liberated FAs, was separated from the aqueous layer containing urea by filtration. The petroleum ether layer was washed with $5 \% \mathrm{NaCl}$ solution to remove any remaining urea. The petroleum ether fraction was dried over anhydrous $\mathrm{Na}_{2} \mathrm{SO}_{4}$. The solvent was
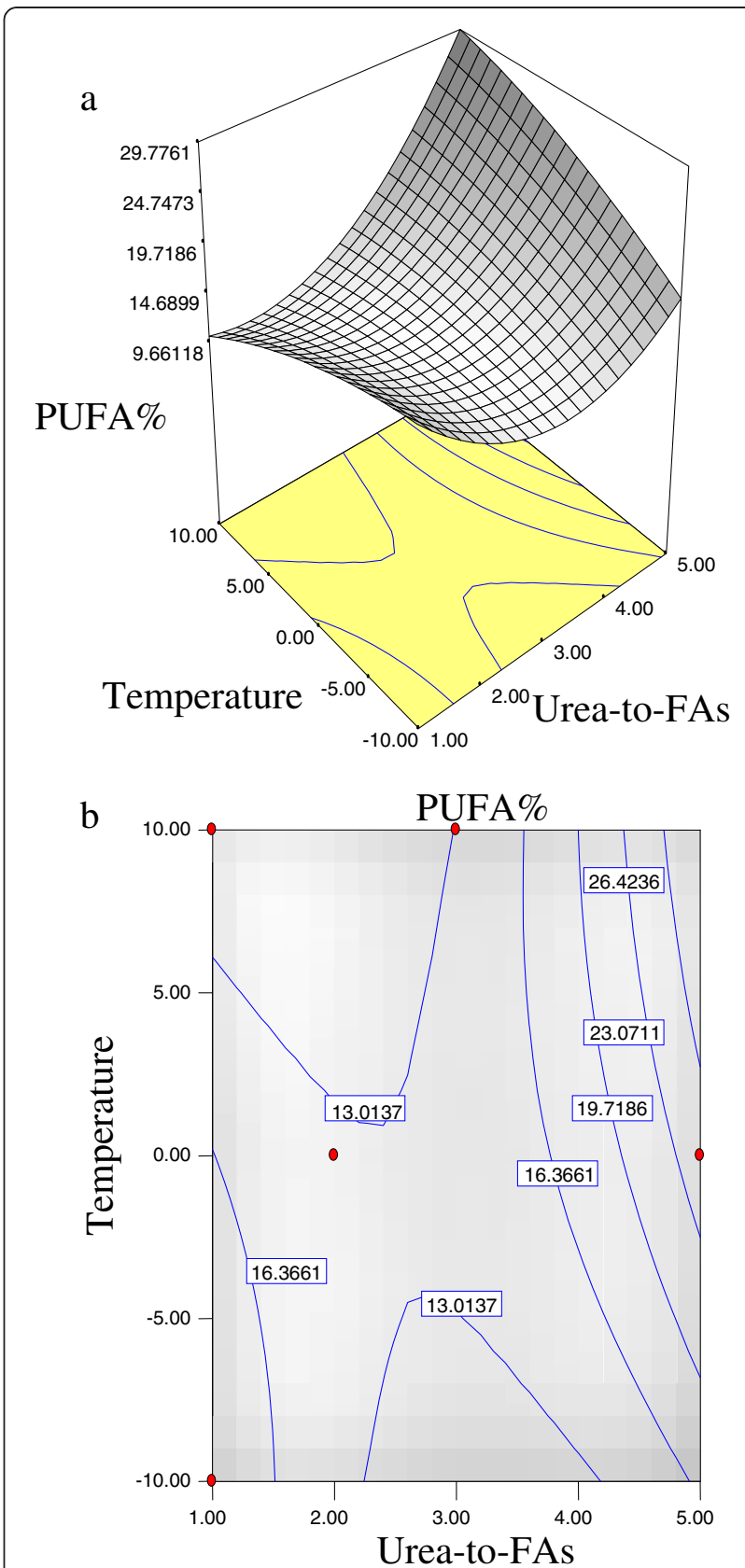

Figure 12 Response surface (a) and contour plots (b) for the effect of the urea-to-FAs ratio $\left(X_{1}, w / w\right)$ and crystallization temperature $\left(X_{2},{ }^{\circ} \mathrm{C}\right)$ on the PUFA\% $(\mathrm{LA})\left(Y_{8}\right)$ of UCF.

removed using a rotary evaporator with water bath temperature at $65^{\circ} \mathrm{C}$ and the FAs converted to FAME for gas chromatography (GC) analysis according to [6]. FAs were analyzed with Shimadzu GC-17A with a BPX70 column $(30 \mu \times 0.25 \mu \mathrm{mm} \times 0.25 \mu \mathrm{m})$. Injection and detection (FID) temperatures were set at $260^{\circ} \mathrm{C}$ and $280^{\circ} \mathrm{C}$, respectively and nitrogen was used as the carrier gas with flow rate of $0.3 \mathrm{~mL} / \mathrm{min}$. The split ratio was 1:39. 

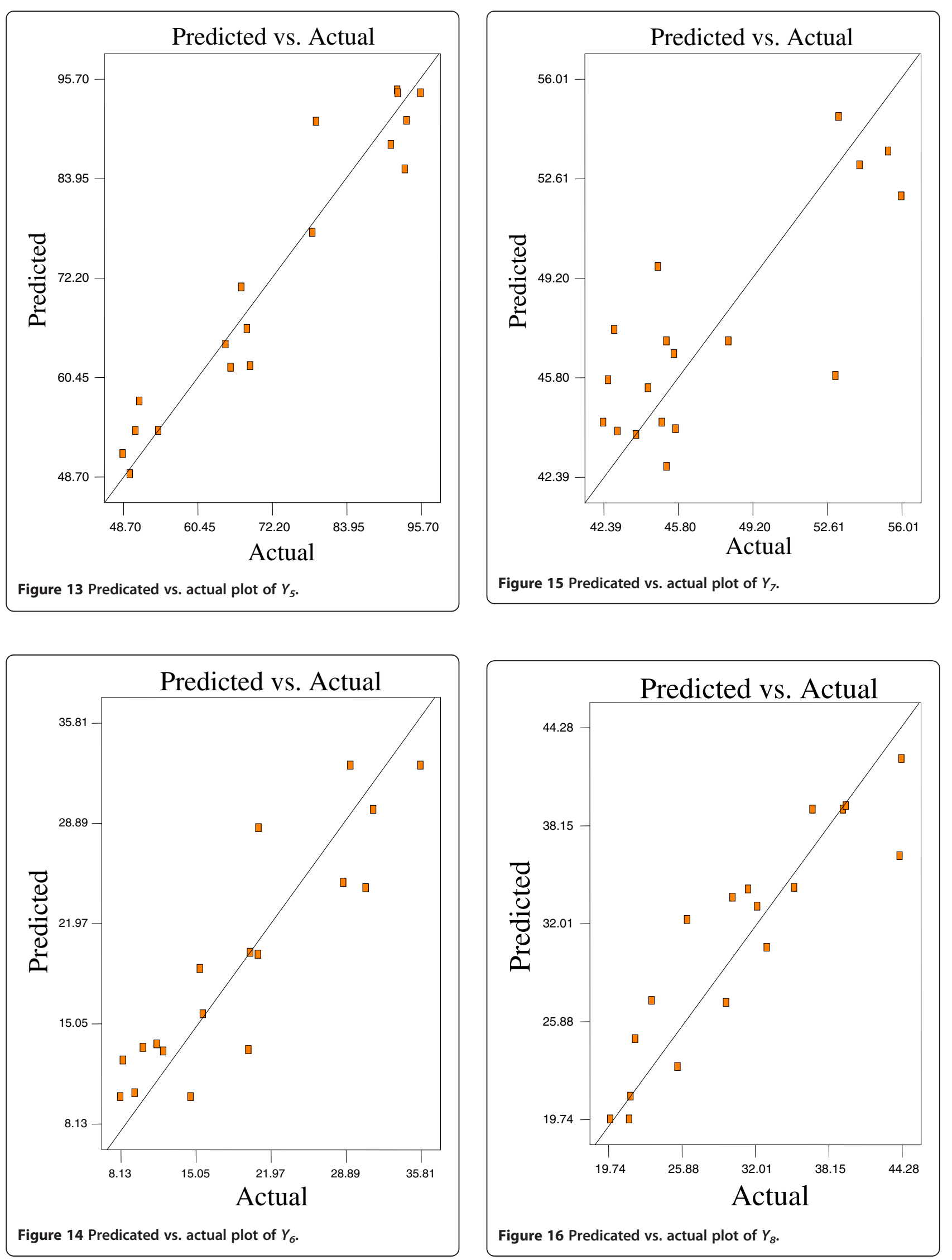
Table 13 Independent variables and their levels for D-optimal design of the fatty acids separation

\begin{tabular}{lcccc}
\hline Independent variables & & \multicolumn{3}{c}{ Variable levels } \\
\cline { 2 - 5 } & & $\mathbf{- 1}$ & $\mathbf{0}$ & $\mathbf{+ 1}$ \\
\hline The urea-to-FAs ratio $(\mathrm{w} / \mathrm{w})(\mathrm{g} / \mathrm{g})$ & $x_{1}$ & 1 & 3 & 5 \\
Crystallization temperature $\left({ }^{\circ} \mathrm{C}\right)$ & $X_{2}$ & -10 & 0 & 10 \\
Crystallization time $(\mathrm{h})$ & $x_{3}$ & 8 & 16 & 24 \\
\hline
\end{tabular}

\section{Experimental design and statistical analysis}

A three-factor D-optimal design was employed to study the responses, after urea inclusion fractionation. The yield of NUCF $\left[Y_{1}\right.$ in \% by wt], SFAs (palmitic and stearic acids) $\left[Y_{2}\right.$ in \%], MUFA (OA) $\left[Y_{3}\right.$ in \%] and PUFA (LA) $\left[Y_{4}\right.$ in \%] are shown in equations $1,2,3$ and 4 respectively. The yield of UCF $\left[Y_{5}\right.$ in \%], SFAs (palmitic and stearic acids) $\left[Y_{6}\right.$ in \%], MUFA (OA) $\left[Y_{7}\right.$ in \%] and PUFA (LA) $\left[Y_{8}\right.$ in \%] after urea inclusion fractionation are shown in equations $5,6,7$ and 8 respectively. An initial screening step was carried out using the technique describe by [5] to select the major response factors and their values.

The independent variables were $X_{1}, X_{2}$ and $X_{3}$ representing the urea-to-FAs ratio $(\mathrm{w} / \mathrm{w})$, crystallization temperature $\left({ }^{\circ} \mathrm{C}\right)$, and crystallization time (h). The settings for the independent variables were low and high values: urea-to-FAs ratio of 1 and 5; crystallization temperature of -10 and 10 and crystallization time of 8 and 24. Each variable was coded at three levels: $-1,0$, and +1 . A quadratic polynomial regression model was assumed for predicting individual $\mathrm{Y}$ variables. The model proposed for each response of $Y$ was:

$$
Y=\beta_{0}+\Sigma \beta i x i+\Sigma \beta i i x i^{2}+\Sigma \Sigma \beta i j x i x j
$$

Where $B_{O} ; B i$; $B i i$ and $B i j$ are constant, linear, square and interaction regression coefficient terms, respectively, and $x i$ and $x j$ are independent variables. The goodness of fit of the model was evaluated by the coefficient of determination $R^{2}$ and the analysis of variance (ANOVA).

\section{Competing interests}

The authors declare that they have no competing interests.

\section{Authors' contributions}

JS developed the concept, analyzed the data and drafted the manuscript. BMA performed the separation method, optimization study and statistical analysis. NS advised on the methods of tests. All authors read and approved the final manuscript.

\section{Acknowledgment}

We thank UKM and the Ministry of Science and Technology for research grant UKM-GUP-NBT-08-27-113, OUP-2012-139 and UKM-OUP-MI-2011.

Received: 9 December 2011 Accepted: 10 February 2012

Published: 2 July 2012

\section{References}

1. Hosamani KM, Katagi KS: Characterization and structure elucidation of 12- hydroxyoctadec-cis-9-enoic acid in Jatropha gossypi folia and Hevea brasiliensis seed oils: a rich source of hydroxyl fatty acid. Chem Phys Lipids 2007, 152:9-12.

2. Smolinske SC: Handbook of Food, Drug, and Cosmetic Excipients. Michigan, USA: Taylor \& Francis, Inc; 1992:247-248.

3. Lui S, Zhang C, Hong P, Ji H: Concentration of Docosahexanoic acid (DHA) and eicosapentanoic acid (EPA) of tuna oil by urea complexation: optimizing of process parameters. J Food Eng 2004, 73:203-209.

4. Yamamura R, Shimomura Y: Industrial High-Performance Liquid Chromatography Purification of Docosapentaenoic Acid Ethyl Ester from Single-Cell Oil. Ibid 1997, 74:1435-1440.

5. Wu M, Ding H, Wang S, Xu Sh: Optimization conditions for the purification of linoleic acid from sunflower oil by urea complex fractionation. J Am Oil Chem Soc 2008, 85:677-684.

6. Fie CY, Salimon J, Said M: Optimisation of urea complexation by Box-Behnken design. Sains Malays 2010, 39:795-803.

7. Salimon J, Abdullah R: Physicochemical properties of Malaysian Jatropha curcas seed oil. Sains Malays 2008, 37:379-382.

8. Guil-Guerrero $J$, Belarbi E: Purification process for cod liver oil polyunsaturated fatty acids. J Am Oil Chem Soc 2001, 78:477-484.

9. Abu-Nasr AM, Holman RT: Highly unsaturated fatty acids. II. Fractionation by urea inclusion compounds. J Am Oil Chem Soc 1954, 31:16-31.

10. Shucheng L, Chaohua Z, Pengzhi H, Hongwu J: Concentration of docosahexaenoic acid (DHA) and eicosapentaenoic acid (EPA) of tuna oil by urea complexation: optimization of process parameters. J Food Eng 2006, 73:203-209.

11. Ratnayake WMN, Olsson B, Matthews D, Ackman RG: Preparation of omega-3 PUFA concentrates from fish oils via urea complexation. Lipid 1988, 90:381-386.

12. Hayes DG, Bengtsson YC, Van Alstine JM, Setterwall FN: Urea complexation for the rapid, ecologically responsible fractionation of fatty acid from seed oil. J Am Oil Chem Soc 1998, 75:1403-1409.

13. Salimon J, Abdullah BM, Salih N: Hydrolysis optimization and characterization study of preparing fatty acids from Jatropha curcas seed oil. Chem Cent J 2011, 5:67.

doi:10.1186/1752-153X-6-65

Cite this article as: Salimon et al:: Selectively increasing of polyunsaturated (18:2) and monounsaturated (18:1) fatty acids in Jatropha curcas seed oil by crystallization using D-optimal design. Chemistry Central Journal 2012 6:65.

\section{Publish with ChemistryCentral and every scientist can read your work free of charge \\ "Open access provides opportunities to our colleagues in other parts of the globe, by allowing anyone to view the content free of charge." W. Jeffery Hurst, The Hershey Company.}

- available free of charge to the entire scientific community

- peer reviewed and published immediately upon acceptance

- cited in PubMed and archived on PubMed Central

- yours - you keep the copyright

Submit your manuscript here:

http://www.chemistrycentral.com/manuscript/

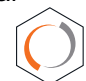

ChemistryCentral 